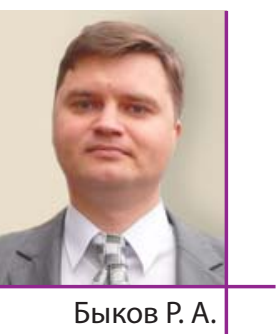

Быков Р. А., К.Т.Н., доцент,

Харьковский национальный университет строительства и архитектуры (ХНУСА), ул. Сумская, 40, г. Харьков, 61002,

凶 romanbykov1009@gmail.com \$ +38 (063) 3186120

Токарев М. Н., К.Т.н., доцент,

Харьковский национальный университет строительства и архитек-

туры (ХНУСА), ул. Сумская, 40, г. Харьков, 61002,

凶 mixtoker@meta.ua $\%$ +38 (098) 2142600

Юнис Башир, к.т.н., доцент кафедры строительной механики,

Харьковский национальный университет строительства и архитек-

туры (ХНУСА), ул. Сумская, 40, г. Харьков, 61002,

$凶$ docbasheer01@gmail.com $\%$ +38 (093) 6610494 ,

Муна Абдалхкем, аспирант,

Харьковский национальный университет городского хозяйства

им. А. Н. Бекетова, вул. Маршала Бажанова, 17, г. Харков, 61002,

凶 sesonoor@yhoo.com, тел.: +38 (093) 2887700
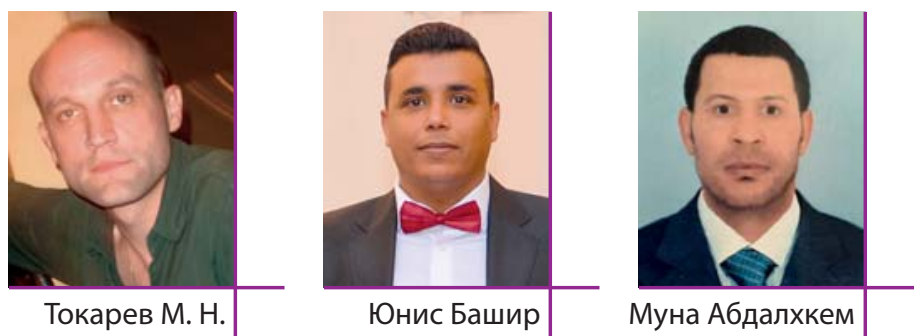

R. Bykov, Ph.D, asst. prof.,

Kharkiv National University of Civil engineering and Architecture,

Str. Sumy, 40, Kharkiv, 61002,

凶romanbykov1009@gmail.com * +38 (063) 3186120

M. Tokarev, Ph.D, asst. prof.,

Kharkiv National University of Civil engineering and Architecture,

Str. Sumy, 40, Kharkiv, 61002,

凶 mixtoker@meta.ua $\%+38$ (098) 2142600

Basheer N. Younis, Ph. D., assistant professor of structural mechanics Department, Kharkiv National University of Construction and Architecture,

Str. Sumy, 40, Kharkiv, 61002

$凶$ docbasheer01@gmail.com $\approx+38$ (093) 66104 94,

Muna Abdalhkem, graduate student,

Kharkiv National University of Municipal Economy. A.N. Beketova,

Str. Marshal Bazhanov, 17, Kharkiv, 61002,

凶 sesonoor@yhoo.com, +38 (093) 2887700

\title{
ЭКСПЕРЕМЕНТАЛЬНЫЙ АНАЛИЗ ВЛИЯНИЯ ЦИКЛИЧЕСКИХ КЛИМАТИЧЕСКИХ ФАКТОРОВ НА ПРОЧНОСТЬ КЛЕЕВОГО СОЕДИНЕНИЯ БЕТОННЫХ БЛОКОВ
}

\section{ЕКСПЕРИМЕНТАЛЬНИЙ АНАЛІЗ ВПЛИВУ ЦИКЛІЧНИХ КЛІМАТИЧНИХ ФАКТОРІВ НА МІЦНОСТІ КЛЕЙОВИХ З'ЄДНАНЬ БЕТОННИХ БЛОКІВ}

\section{EXPERIMENTAL ANALYSIS OF THE INFLUENCE OF CYCLIC CLIMATIC FACTORS ON STRENGTH OF ADHESIVE CONNECTION OF CONCRETE BLOCKS}

Анотация. В статье рассматривается результат экспериментального влияния циклических климатических факторов на прочность клеевого соединения строительных конструкций для тропически - прибрежной климатической зоны Ливии.

Ключевые слова: полимерная композиция, арматура, бетонные конструкции, климатический фактор, клеевое соединенение.

Анотація. У статті розглядається результат експериментального впливу циклічних кліматичних факторів на міцність клейового з'єднання будівельних конструкцій для тропічно - прибережній кліматичної зони Лівії.

Ключові слова: полімерна композиція, арматура, бетонні конструкції, кліматичний фактор, клейове з'єднання.

Annotation. The article examines the result of the experimental influence of cyclic climatic factors on the strength of the glued joint of building structures for the tropical - coastal climatic zone of Libya.

Key words: polymer composition, reinforcement, concrete structures, climatic factor, glue joint.

\section{Введение}

Анализ особенностей природно-климатических условий Ливии показал, что агрессивное тепловое воздействие на железобетонные конструкций, которые склеены полимерными клеями, приводит к снижению механических свойств бетона и арматуры, разрушению бетона вследствие его растрескивания или отколов, образованию температурно-усадочных и силовых трещин и потере предварительного напряжения арматуры, а также ухудшению условий совместной работы бетона и арматуры [1, 2]. Опыт применения эпоксидных и акриловых составов в строительстве подтверждает преимущества клеевых соединений по сравнению с цементными растворами [3-9], но это относится только к конструкциям, которые эксплуатируются в умеренных климатических зонах. В научной литературе не встречаются описания эксперементально доказанной эффективности различных клеевых составов при экспуатации в условиях влияния специфических климатических условий. Возникает необходимость изучения влияния циклических климатических факторов на прочность клеевого соединения испытуемых бетонных блоков для анализа прочности склеенных образцов и их устойчивости к влиянию различных агрессивных экспуатационных факторов.

Целью настоящей статьи является экспериментальное определение влияния циклических климатических факторов на прочность клеевого соединения строительных конструкций в зависимости от времени выдержки в климатической камере для тропически - прибрежной климатической зоны Ливии.

\section{Разработка полимерной композиции}

В рамках проведенного авторами эксперимента по определению эффективности метода восстановления строительных конструкций, ранее была разработана полимерная композиция наполненная минеральным дисперсным наполнителем, которая способна твердеть при повышенных температурах [10]. Состав полимерной композиции приведен в табл. 1.

Таблица 1.

Состав разработанной полимерной композиции

\begin{tabular}{|c|c|c|}
\hline Наименование & Обозначение НТД & $\begin{array}{l}\text { Количество } \\
\text { компонента, } \\
\text { масс.ч. }\end{array}$ \\
\hline \multicolumn{3}{|c|}{ Смоляная модифицированная часть: } \\
\hline Эпоксидиановая смола ЭД-20 & ДСТУ - 2093-92 & 100 \\
\hline $\begin{array}{l}\text { Олигоэфиртриэпоксидный } \\
\text { олигомер марки Лапроксид- } \\
503 \text { (ГЭПТ-2) }\end{array}$ & ТУ-6-01-221-740-86 & 5 \\
\hline Амирол-М & TУ-38.301-48- 49-97 & 1 \\
\hline \multicolumn{3}{|c|}{ Отвердитель: } \\
\hline $\begin{array}{l}\text { Цианэтилдиэтилентриамин } \\
\text { марки УП-0633 }\end{array}$ & ТУ-6- $05-1863-78$ & $10-16$ \\
\hline $\begin{array}{l}\text { Полиэтиленполиамин марки } \\
\text { ПЭПА }\end{array}$ & ТУ-38.30340-83 & 4-6 \\
\hline \multicolumn{3}{|c|}{ Наполнитель: } \\
\hline Диабазовый порошок & ТУ- УССР-89 & $10-20$ \\
\hline
\end{tabular}


Таким образом, разработанная композиция обладает свойствами, которые позволяют использовать ее для инъектирования трещин в кирпичной кладке с целью восстанавления элементов конструкций.

\section{Экспериментальная часть}

В лабораториях кафедр строительных материалов и химии Харьковского национального университета строительства и архитектуры были созданы условия подобные тропической климатической зоне (максимально приближенные к условиям Ливии) и оценено влияние циклических перепадов температуры в условиях солевого тумана на механическую прочность бетонных конструкций. Для этого была изготовлена партия стандартных бетонных балок в количестве 60 штук (рис. 1).

В процессе эксперимента часть балок была разрушена на машине марки П 6330, а затем восстановлена при помощи разработанной полимерной композиции методом инъекцирования. Для оценки эффективности применения разработанных эпоксидных материалов были проведены испытания в климатической камере типа «тепло-влажность» по ГОСТ 9.707-81[12]. Полученные образцы погружались в климатическую камеру на определенный срок согласно программе эксперимента.

Для более точного анализа влияния различных климатических зон регионов Ливии на прочность восстановленных бетонных балок, в климатической камере были созданы условия максимально соответствующие тропически - континентальной (пустынной) и тропически прибрежной климатическим зонам. Каждая из зон была условно разделена на 4 сезона с соответствующими температурно - влажностными характеристиками.

Согласно разработанной программе эксперимента были установлены следующие параметры испытаний:

- $\quad$ количество циклов нагревания-охлаждения - 100

- каждый цикл включает последовательное нагревания исследуемых образцов до температуры $25-60^{\circ} \mathrm{C}$ (в зависимости от моделируемого месяца, выдержки при данной температуре в течение не менее 14 часов с последующим охлаждением до температуры 0-20 ㄷ (в зависимости от моделируемого месяца) на 10 часов.

a)

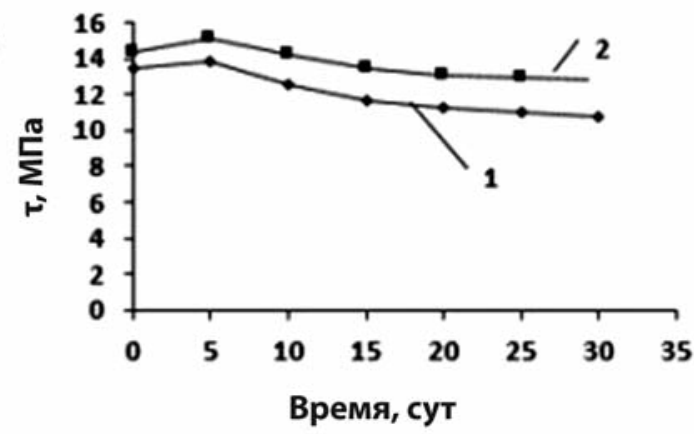

B)

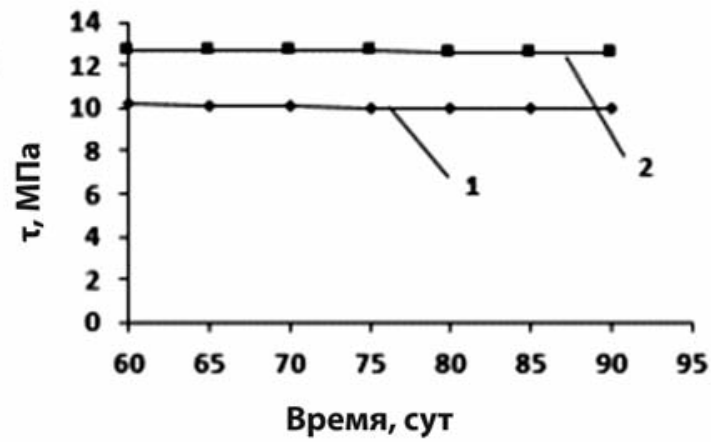

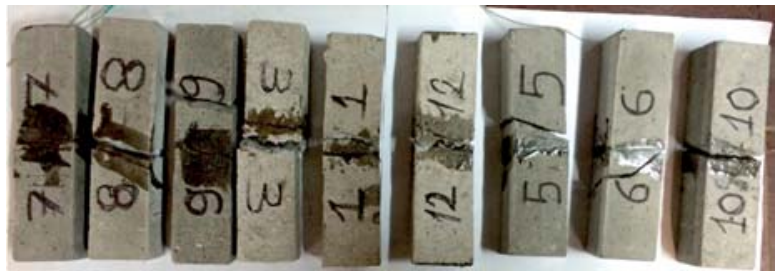

Рис. 1. Изготовленные образцы бетонных балок

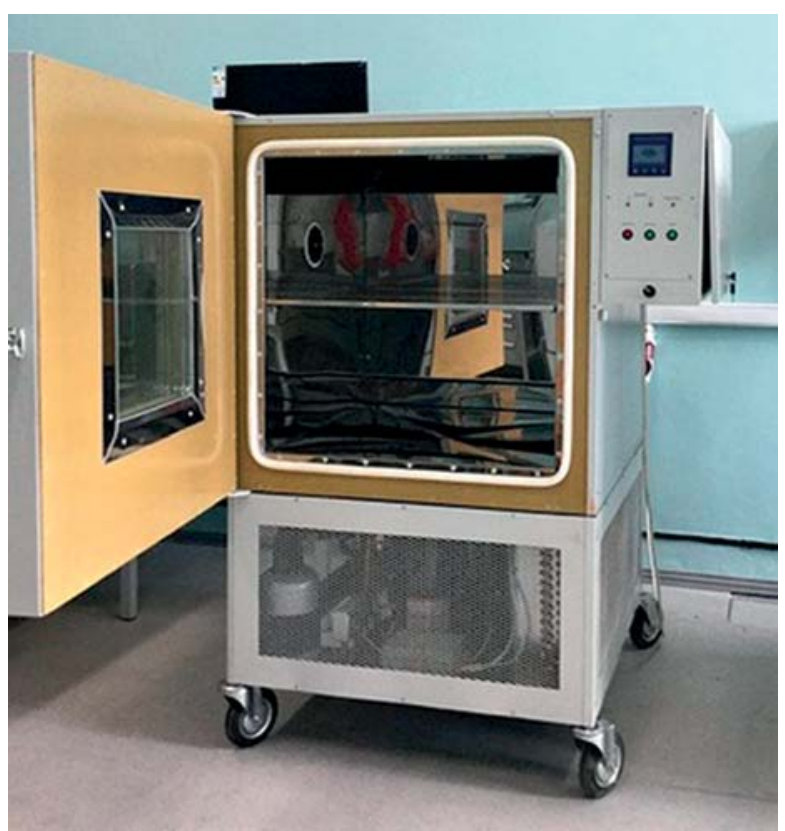

Рис. 2. Испытательная климатическая камера

В течение каждого цикла образец подвергался термическому удару на срок не менее 2 часов при температуре $90^{\circ} \mathrm{C}$ :

- $\quad$ после каждой из контрольных точек эксперимента проводились испытания не менее трех стандартных и восстановленных бетонных балок на прочность при изгибе.

Результаты исследований представлены на рис. 3.

Следующим этапом было испытание на изгиб бетонных балок методом продавливания на экспериментальной установке, процесс испытания представлен на рисунке 4.

б)

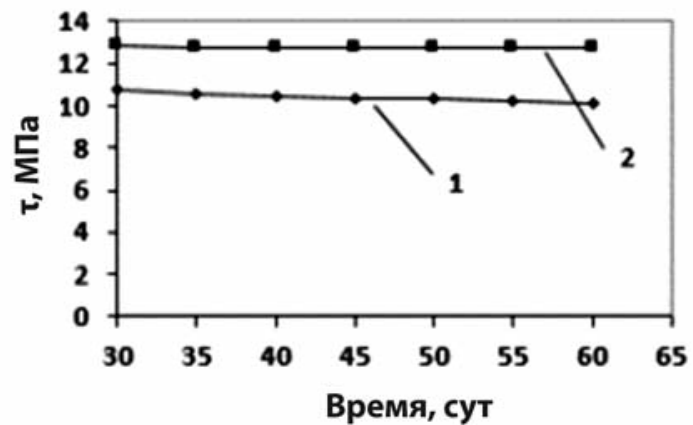

г)

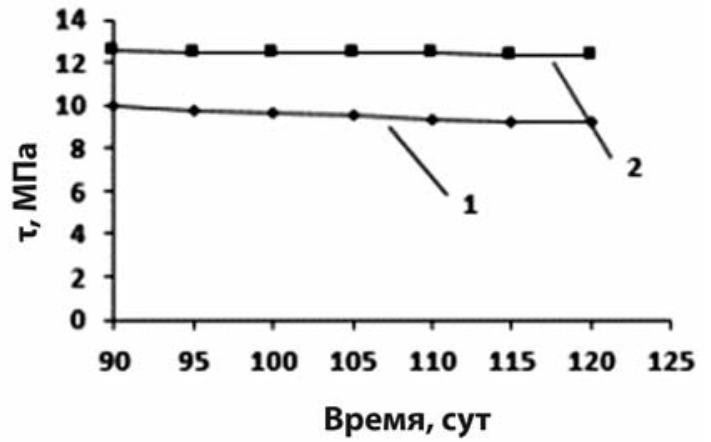

Рис. 3. Изменение прочности бетонных балок от времени выдержки в климатической камере для тропически-прибрежной климатической зоны:

а) декабрь-январь-февраль; б) март-апрель-май; в) июнь-июль-август; г) сентябрь-октябрь-ноябрь 


\section{Обсуждение результатов испытания}

Анализ полученных результатов показывает, что в условиях повышенной влажности в зимний период для эталонных бетонных образцов (кр. 1 рис. 3 (а), в течение первого месяца наблюдается незначительное на 0,3-0,5 МПа повышение прочности бетона, что, по- видимому, связанно с дополнительным твердением бетона за счет избытка влаги, но в течение последующих двух зимних месяцев происходит существенное снижение прочности бетона на 10-15 \% (1,5-2 МПа), вызванное процессами выщелачивания, сульфатной коррозии и карбонизации за счет наличия в солевом тумане, который моделирует условия прибрежной зоны $\mathrm{NaCl},-\mathrm{SO}_{4}$, $-\mathrm{CO}_{2}$ (маленькие 4 и 2) растворенных в воде.

В то же время для восстановленной бетонной балки (кр. 2 рис. 3 (а) снижение прочности бетона составляет всего 5-6 \% (0,7-1МПа ), что, по- видимому, связанно с тем, что разработанная полимерная композиция обладает ограниченной (до 5мм) проникающей способностью, в результате чего в области клеевого соединения происходит закупорка пор бетона, и образуется естественный барьер для миграции солевых ионов и углекислого газа в тело бетона (рис. 5).

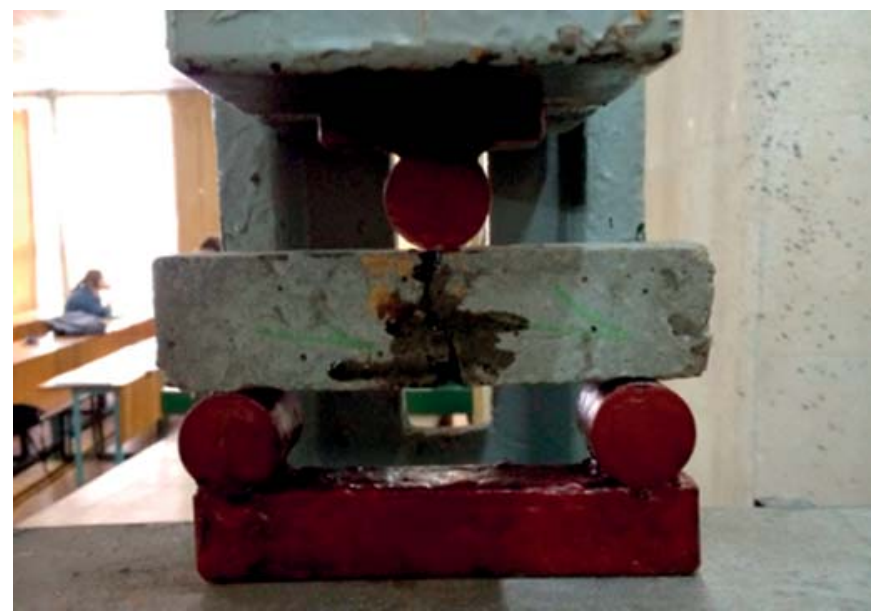

Рис. 4. Экспериментальное испытание бетонных балок при изгибе

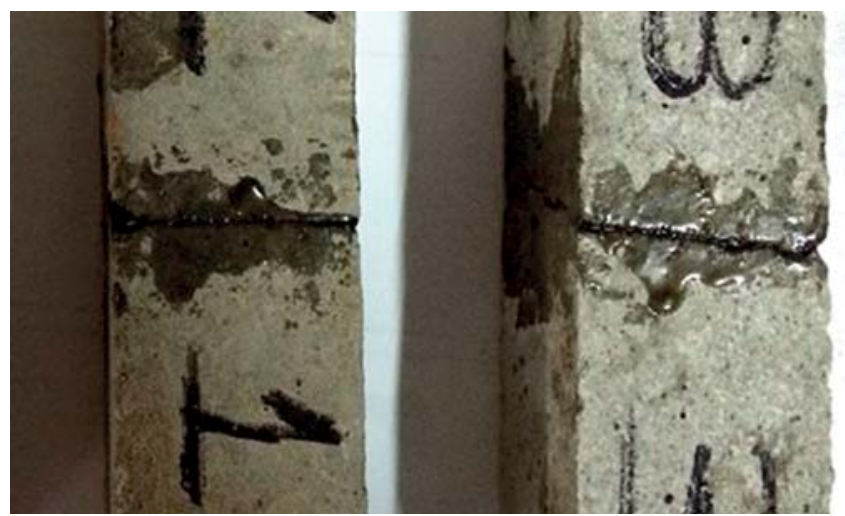

Рис. 5. Клеевое соединение бетонных балок

Кривые 1,2 на рис 3 (б) и 2 (в) показывают, что в весеннелетний период происходит существенное замедление спада прочности за счет того, что данный период характеризуется снижением количества осадков при постоянном приросте среднесуточной температуры, вследствие чего происходит испарение жидкости с поверхности и из тела бетона, которое сопровождается процессом кристаллизации гидроокиси кальция, что приводит к снижению процессов фильтрации и уплотнению бетона [11]. Причем характер данных зависимостей фактически аналогичен как для эталонного, так и для восстановленного образцов.

Как видно из представленных на рис. 3 (г) (кр. 1, 2) данных в осенний период происходит незначительное снижение прочности анализируемых образцов на 0.6-0.8 МПа, вызванное активным испарением влаги из капилляров в условиях повышенной влажности и температуры, однако данный эффект значительно ниже по сравнению с весенним периодом из-за частичной блокировки пор бетона гидроокисью кальция.

\section{Выводы}

1. В ходе испытаний в климатической камере установлено, что в процессе выдержки в модельной климатической среде происходит постепенное снижение прочности бетонных балок, особенно интенсивный процесс наблюдается при моделировании летних месяцев, т. е. с повышением температуры и в условиях повышенной влажности.

2. Применение разработанной полимерной композиции позволяет на 15-20\% повысить прочность восстановленных бетонных балок (по сравнению с эталонными балками). Показано, что использование разработанной эпоксидной композиции позволяет не только повысить прочность образцов, но и более надежно сохранить ее в условиях исследуемых климатических зон.

3. Проведенный эксперементальный анализ влияния циклических климатических факторов на прочность клеевого соединения бетонных блоков, склеенных разработанной эпоксидной композицией позволяет достаточно высоко оценить эффективность данной композиции в условиях, характерных для тропически-прибрежной климатической зоны, такой как в Ливии.

4. Результаты эксперемента позволяют сделать выводы о возможности широкого внедрения разработанной композиции в строительную и реконструкционную практику Ливии.

\section{Литература:}

1. Mouna Abdalhkem., The use of polymer adhesives for the reconstruction of concrete elements of destroyed buildings in libya International Journal of Engineering Sci- ence and Innovative Technology (IJESIT)Volume 4, Issue 4, 2015.

2. Попов В. М., Влияние времени обработки клея в магнитном поле и температуры на прочность клеевых соединений древесины, Научный журнал КубГАУ, №75(01), 2012 года.

3. Баженов Ю.М. Бетонополимеры / Ю.М. Баженов. - М. Стройиздат, 1983. -472 с.

4. Корнеев, А.Д., Ппоксидные полимербетоны / А.Д. Корнеев, Ю.Б. Потапов. - Липецк: ЛГТУ, 2001. - 181с.

5. Соколова Ю.А., Модифицированные эпоксидные клеи и покрытия в строительстве / Ю.А. Соколова, Е.М. Готлиб. - М. : Стройиздат, 1990.- 176 с.

6. Гроздов В.Г., Усиление строительных конструкций / В.Г. Гроздья. - СПб. : Изд-во дом КН +, 2001. - 232

7. Пустовойтова О.М., Деформативность растворов на основе акриловых полимер-растворов // Коммунальное хозяйство городов: Науч.-техн. сб. Вып.23. - К.: Техніка, 2000. - С.80-83.

8. Шутенко Л.Н., Золотов С.М., Гарбуз А.О. Использование акриловых клеев для реконструкции и ремонта зданий и сооружений // Будівельні конструкції: 36. наук. праць. Вип.54. - К.: НДІБК, 2001. - С.810-814.

9. Кривцов Ю.В., Огнезащита железобетонных несущих конструкций тонкослойными покрытиями [ Текст ] / Кривцов Ю.В., Ламкин О.Б., Рубцов В.В., Габдулин Р.Ш. // Мир и безопасность - 2006. - №1, - С. 23-24.

10. Разработка модифицированной эпоксидной композиции пригодной для востановления Строительных конструций в условиях климатической зоны Ливии //Юнис Башир, токарев м.н., савин а.б., муна Абдалхкем.// Строительные материалы и изделия. - 2017. - № 1 -2 С. 78-81.

11. Изотов В.С., Коррозионная стойкость бетонов на смешанном вяжущем. [Текст] / В.С. Изотов, Н.Н.Морозова // Изв. вузов. Строительство.- М., 1997.-12. 12. -С.50-52.

12. ГОСТ 9.707-95. Ддиная система защиты от коррозии и старения. Методы ускоренных испытаний на климатическое старение. [Текст].- Введ. 1996.01.01.- М. Стандартинформ, 1995. - 90с. 